\title{
Bir Kâğıt Fabrikasındaki Kojenerasyon Tesisinin Enerji Ve Ekserji Analizi
}

\author{
Ahmet KAYA*, M. Mustafa DUYMAZ, Muharrem IMAL \\ Kahramanmaraş Sütçü İmam Üniversitesi, Makine Mühendisliği, Kahramanmaraş, Türkiye
}

\begin{abstract}
ÖZET: Bu çalışmada; Türkiye'de çalışmakta olan Kahramanmaraş Kağıt San. ve. Tic. A.Ş. bünyesindeki Kojenerasyon Tesisinin enerji ve ekserji analizleri yapılarak elde edilen sonuçlar değerlendirilmiştir. Kojenerasyon tesisinde belirlenen otuz bir adet düğüm noktasının termodinamik özellikleri dikkate alınarak enerji ve ekserji değerleri hesaplanmıştır. Elde edilen sonuçlara göre ekipmanların ayrı ayrı enerji ve ekserji dengeleri kurulmuş, ortalama kayıp ve yıkıma uğramış olan enerji ve ekserjiler hesaplanmış, kayıp enerji oranı ve yok olan ekserji oranı tespit edilmiştir. Elde edilen sonuçlara göre; toplam enerji kaybının \%42,92'si ile en yüksek enerji kaybı ve toplam yok olan ekserjinin \%87.3'ü ile en yüksek ekserji kaybı oranı olan ekipman, kazan olarak bulunmuştur. Elde edilen termodinamik özellikler yardımıyla Kojenarasyon Sisteminin ısıl ve ikinci yasa verimleri sırasıly \%80.15 ve $\% 32.75$ olarak hesaplanmıştır.
\end{abstract}

Anahtar Kelimeler: Ekserji Analizi, Kojenerasyon Tesisi, İkinci Kanun Analizi, Enerji Analizi, Termodinamik Analiz

\section{Energy and Exergy Analyses of Co-Generation Plant at a Paper Factory}

ABSTRACT: In this study; the results obtained by energy and exergy analysis of the Cogeneration Plant, which operates in Turkey, within the Kahramanmaraş Kâğıt San. ve Tic. A.Ş. were evaluated. Energy and exergy values were calculated considering thermodynamics properties of thirty-one node points, which identified in Cogeneration Plant. Individual energy and exergy balance of equipment were established based on the obtained results. Average lost and destroyed energy and exergy were calculated. Lost energy rate and vanished exergy rate were determined. According to the results, the boiler was found to be highest exergy loss rate equipment with $42,92 \%$ of the total energy loss and $87,3 \%$ of the exergy loss. The thermal and second law efficiency of Cogeneration Plant were calculated $80.15 \%$ and $32.57 \%$, respectively, with the help of obtained thermodynamic properties.

KeyWords: Exergy Analysis, Cogeneration Plant, Second Law Analysis, Energy Analysis, Thermodynamic Analysis

\section{GíRiş}

İnsan nüfusunun ve teknolojiye olan ihtiyacının sürekli artışına paralel olarak sanayi devriminin başından bu yana ülkeler sürekli sanayileşmekte, bu değişimin kaçınılmaz sonucu olarak ise insanoğlunun enerji ihtiyacı günden güne artmaktadır. Enerji ihtiyacındaki bu artışı karşılayacak olan enerji kaynakları ise gün geçtikçe azalmaktadır. Tüm bunlar göz önüne alındığında, enerji üretim ve tüketim miktarı her geçen gün daha fazla önem arz etmektedir.

Sanayi kuruluşlarının enerji ihtiyaçları, kamu tüketim değerlerinin oldukça üstünde olmakta ve birçok sanayi kuruluşunda elektrik enerjisinin yanı sıra su, su buharı, yağ vb. maddelerin yardımıyla termal enerji kullanımı da prosese dâhil olmaktadır. Elektrik ve buhar kullanımının bir arada olduğu proseslerde bu iki ihtiyacı da aynı zamanda karşılayabilecek sistemler kurulmuştur. Bu sistemlere Kojenerasyon Tesisi adı verilmektedir. Kojenerasyon sistemleri; lokal olarak uygulanabilmesi, prosesin bir çok farklı ihtiyacını bir arada karşılayabilmesi, yüksek verimlilik değerlerine sahip olması ve değişken proses ihtiyaçlarına karşı toleranslı olması gibi sebeplerle, ilerleyen teknoloji ile birlikte sanayi kuruluşlarının ayrılmaz bir parçası haline gelmiştir. $\mathrm{Bu}$ tesislerin yüksek verimlerde kullanılabilmesi için öncelikle tesisin enerji analizi yapılmalı, enerji analizinin yanı sıra ekserji analizi de yapılarak sistem ekipmanları ve sistem genelinde verimli olmayan noktalar tespit edilip, bu noktalarda yapılabilecek düzeltmeler belirlenmelidir.

Literatürde enerji santrallerinin enerji ve ekserji analizine yönelik çalışmalar mevcuttur. Ballı (2008); Eskişehir de kurulu bulunan gaz türbin motorlu kojenerasyon ve gaz-dizel motorlu trijenerasyon sistemlerinin enerji, ekserji ve eksergoekonomik analizini yapmıştır [1]. Yazıcı ve Selbaş (2011) ideal Rankine çevrimiyle çalışan bir buharlı güç santralinin enerji ve ekserji analizini yapmışlardır. Sistemin toplam tersinmezliğini hesaplayarak en fazla tersinmezlik

* Sorumlu Yazar: kaya38@ksu.edu.tr 
üreten elemanı belirlemişlerdir [2]. Rahim ve Gündüz (2013) gaz türbinli bir kojenerasyon santralinin enerji ve ekseji analizini yaparak santraldeki kayıları belirlemişlerdir [3]. Colpan ve Yesin (2006) gaz/buhar çevrimli kojenerasyon tesisine termodinamik ve ekonomik analiz uygulamışlardır [4]. Coşkun vd. (2013) Türkiye'de çalışmakta olan Çayırhan termik santralinin enerji ve ekserji analizini yapmışlar, elde edilen termodinamik özellikler yardımı ile termik santralin 1sıl ve ikinci yasa verimlerini belirlemişler ve ekserji kayıplarının en yüksek olduğu ekipmanları tespit etmişlerdir [5]. Sevilgen (2004) gaz-türbin gruplu bir kojenerasyon sisteminin ekserjoekonomik analizini yapmıştır [6]. Rosen ve Dinçer (2004) kömür yakıtlı bir enerji santralinde farklı ölü hal şartları belirleyerek enerji ve ekserji analizi yapmışlardır [7]. Ünal ve Özkan (2014), Tunçbilek Termik Santralinde sistemin geneline ve her bir ekipmana ayrı ayrı enerji ve ekserji analizini yaparak sistem ekipmanlarından enerji ve ekserji kayıplarının en yoğun olduğu ekipmanı belirlemiş ve bu ekipmanda yapılabilecek düzeltmelere dair önerilerde bulunmuşlardır [8]. Kaya (2008) ideal Rankine çevrimine göre çalışan bir buharlı güç çevrimine ekserji analizini uygulamış ekserjitik verimin artması için yapılabilecek iyileştirmeleri belirlemişstir [9].

Bu çalışmada, Kahramanmaraş'ta çalışmakta olan Kahramanmaraş Kağıt San. ve Tic. A.Ş.'de kömür yakıtlı kojenerasyon tesisinin her bir ünitesine enerji ve ekserji analizi yapılarak, enerji ve ekserji verimleri ile enerji ve ekserji kayıpları belirlenmiştir. Elde edilen sonuçlar değerlendirilmiş ve kayıpların azaltılması için çözüm önerileri sunulmuştur.

\section{SÜREKLİ AKIŞLI SÜREKLİ AÇIK SISTEMLERİN ENERJI ANALIZLERİ}

Genel bir sürekli akış sistemi için kütlenin korunumu,

$$
\sum_{g} \dot{m}=\sum_{c} \dot{m}
$$

şeklindedir.

Sürekli akışlı açık sistemler için enerjinin korunumu aşağıdaki gibi yazılabilir:

$$
\dot{E}_{g}-\dot{E}_{c ̧}=d E_{\text {sistem }} / d t=0
$$

Enerjinin korunumu: $\quad \dot{E}_{g}=\dot{E}_{c}$

$$
\left(\begin{array}{c}
\text { Birim zamanda } \\
\text { ssl, iş veya kütle ile } \\
\text { kontrol hacmine } \\
\text { giren enerji }
\end{array}\right)=\left(\begin{array}{c}
\text { Birim zamanda } \\
\text { isı, iş veya kütle ile } \\
\text { kontrol hacminden } \\
\text { çıkan enerji }
\end{array}\right)
$$

Akışkanın birim kütlesinin enerjisi $\theta=h+k e+p e=h+\left(V^{2} / 2\right)+g z \quad$ olduğundan sürekli akışlı açık bir sistemde 1sı, iş ve kütle ile aktarılan enerji için enerjinin korunumu denklemi aşağıdaki gibi olur.

$$
\dot{Q}-\dot{W}=\sum_{c} \dot{m}\left(h+\frac{V^{2}}{2}+g z\right)-\sum_{g} \dot{m}\left(h+\frac{V^{2}}{2}+g z\right)
$$

Bir girişli ve bir çıkışlı sürekli akışlı açık sistem için enerjinin korunumu denklemi:

$$
\dot{Q}-\dot{W}=\dot{m}\left(h_{2}-h_{1}+\frac{V_{2}^{2}-V_{1}^{2}}{2}+g\left(z_{2}-z_{1}\right)\right)
$$

şeklindedir.

Bu denklemler kütle debisi $\dot{m}$ ile bölünürse, birinci yasa birim kütle için ifade edilmiş olur.

$$
q-w=h_{2}-h_{1}+\frac{V_{2}^{2}-V_{1}^{2}}{2}+g\left(z_{2}-z_{1}\right)
$$

Kinetik ve potansiyel enerji değişimleri ihmal edilirse, yukarıda verilen denklem aşağıdaki gibi olur.

$$
q-w=h_{2}-h_{1}
$$

Isıl verim ifadesi aşağıda verilen denklem kullanılarak elde edilmiştir [10];

$$
\eta=\frac{\dot{W}_{\text {net }}}{\dot{Q}_{\text {giren }}}
$$

\subsection{Ekserji Bileşenleri}

Nükleer, manyetik, elektriksel ve yüzey gerilme etkilerinin yokluğunda bir sistemin toplam ekserjisi dört ayrı bileşene bölünebilir: fiziksel ekserji $\dot{E} x^{P H}$, kinetik ekserji $\dot{E} x^{K N}$, potansiyel ekserji $\dot{E} x^{P T}$ ve kimyasal ekserji $\dot{E} x^{C H}$

$\dot{E} x=\dot{E} x^{P H}+\dot{E} x^{K N}+\dot{E} x^{P T}+\dot{E} x^{C H}$

Özgül ekserji aşağıdaki şekilde tanımlanır $[1,8]$.

$$
e x=e x^{P H}+e x^{K N}+e x^{P T}+e x^{C H}
$$

Saf maddelerin fiziksel ekserjisi genel olarak;

$$
e x^{P H}=\left(u-u_{0}\right)-\mathrm{P}_{0}\left(v-v_{0}\right)-T_{0}\left(s-s_{0}\right)
$$


Fiziksel ekserji kısaca;

$$
e x^{P H}=\left(h-h_{0}\right)-T_{0}\left(s-s_{0}\right)
$$

Toplam fiziksel ekserji akısı ise;

$$
\dot{E} x^{P H}=\dot{m} \cdot e x^{P H}
$$

şeklinde yazılabilir.

Kimyasal ekserjiyi değerlendirirken çeşitli alternatif teoriler ortaya atılmıştır. Saf maddeler için standart kimyasal ekserji değerleri ilgili çizelgelerden okunarak hesaplamalarda kullanılabilir. Gaz karışımları için ise aşağıdaki eşitlikten yararlanılır $[1,8]$.

$$
\bar{e} x^{C H}=\sum x_{k} \bar{e} x_{k}^{C H}+\bar{R} T_{0} \sum x_{k} \ln x_{k}
$$

Bu denklemde $e x_{k}^{C H}$ terimi için standart kimyasal ekserji $2.5 \mathrm{~kJ} / \mathrm{kg}$ olarak seçilmiştir [8].

\subsection{Ekserji Kaybı ve Yıkımı}

Sistemin herhangi bir elemanı için birim zamanda kaybedilen ekserji miktarı Eky;

$$
\dot{E} x_{k y}=\dot{E} x_{Q}-\dot{E} x_{W}+\sum \dot{E} x_{m, g}-\sum \dot{E} x_{m, s}
$$

$$
\dot{E} x_{k y}=\sum\left(1-\frac{T_{0}}{T}\right) Q-W+\sum \dot{m} e_{g}-\sum \dot{m} e x_{\zeta}
$$

şeklinde ifade edilir. Sistemin tümünde yok edilen ekserji ise, her bir elemanda yok edilen ekserjinin toplamidir.

$$
\sum_{x=1}^{n} \dot{E} x_{k y_{x}}=\dot{E} x_{k y_{1}}+\dot{E} x_{k y_{2}}+\dot{E} x_{k y_{3}}+\ldots+\dot{E} x_{k y_{n}}
$$

Herhangi bir ünitede veya elemanda yok edilen ekserjinin sistemin tümünde yok edilen ekserjiye oranı $\left(\mathrm{y}_{\mathrm{k}}\right)$, ele alınan birimin kayıp enerjisinin ne kadarına neden olduğunu gösterir [8].

İkinci kanun verimi ise aşağıda verilen formülle ifade edilir [8];

$$
\eta_{I I}=1-\frac{\text { kaylp ekserji }}{\text { giren ekserji }}=1-\frac{\dot{E} x_{k y}}{\dot{E} x_{g}}
$$

\section{MATERYAL METOD}

$\mathrm{Bu}$ çalışmanın yapılacağı kojenerasyon tesisi, Türkiye'de Kahramanmaraş ilinde bulunan Kahramanmaraş Kağıt Sanayi ve Ticaret A.Ş. bünyesinde çalışmaktadır. Tesis Kağıt Fabrikasının prosesinde kullanılan buhar ve elektrik ihtiyacını karşılamak için kurulmuştur. Kojenerasyon tesisinde 11.7MWe gücünde bir adet buhar türbini, 59MW (1sil) güce sahip bir adet pulverize kömürlü buhar kazanı, bir adet kondenser, 1siticı grubu ve yardimci elemanlar bulunmaktadır. Isıtıcı grubu bir adet degazör ve bir adet yüksek basınçlı ısıtıcıdan oluşmaktadır.

Şekil 1'de verilen akış diyagramına göre, tesiste 31 adet düğüm noktası belirlenmiş ve belirlenen bu noktaların sıcaklık, basınç ve debi değerleri ölçülmüştür. Ölçülen bu değerlere göre her bir noktadaki akışkanın Termodinamik özellikleri hesaplanmış ve bulunan değerler Tablo 1'de gösterilmiştir [11]. 


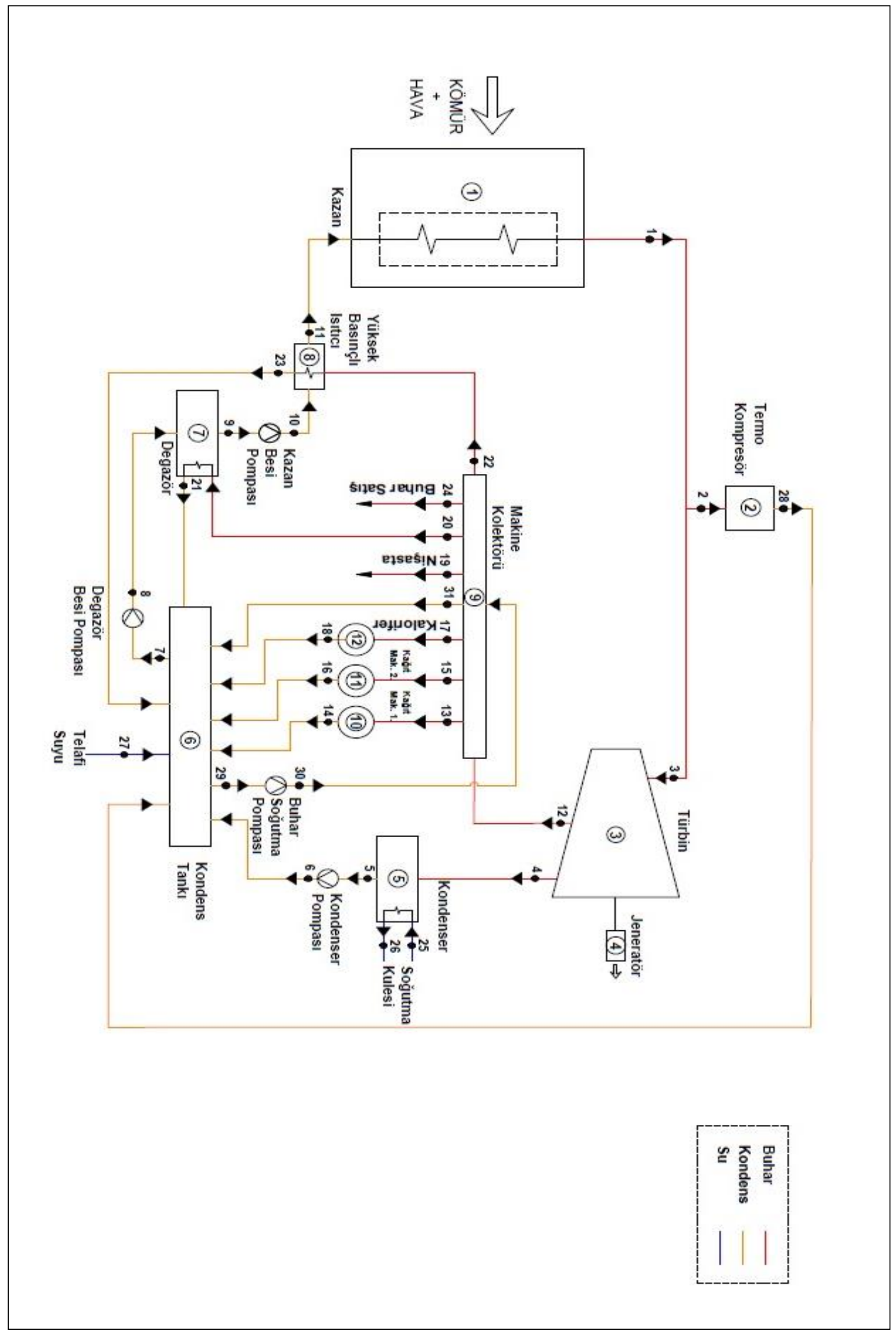


Tablo 1. Kojenerasyon Tesisi’ne Ait Düğüm Noktaları ve Termodinamik Özellikleri

\begin{tabular}{|c|c|c|c|c|c|c|}
\hline \multirow{2}{*}{$\begin{array}{c}\text { Düğümm } \\
\text { No }\end{array}$} & \multirow{2}{*}{$\begin{array}{c}\text { Faz } \\
\text { Durumu }\end{array}$} & Sicaklık & Basınç & Debi & Entalpi & Entropi \\
\hline & & $\mathbf{T}\left({ }^{\circ} \mathbf{C}\right)$ & $\mathbf{P}($ bar $)$ & $\dot{\mathbf{m}}($ ton$/ \mathrm{s})$ & h(kJ/kg) & s(kJ/kg.K) \\
\hline 1 & Buhar & 458.8 & 41.72 & 61.25 & 3348.4 & 6.942 \\
\hline 2 & Buhar & 458.8 & 41.72 & 3.05 & 3348.4 & 6.942 \\
\hline 3 & Buhar & 456.6 & 36.07 & 58.2 & 3350.91 & 7.010 \\
\hline 4 & Buhar & 50.272 & 0,06 & 11.679 & 2591.71 & 8.069 \\
\hline 5 & S1k1ştırılmş sıv1 & 50.272 & 0,4 & 11.679 & 210.524 & 07073 \\
\hline 6 & S1k1ştırılmş sıv1 & 50.272 & 5.75 & 11.679 & 210.985 & 0.7070 \\
\hline 7 & S1k1ştırılmş sıv1 & 87.5 & 1 & 61.25 & 366.48 & 1.16353 \\
\hline 8 & S1kıştırılmş sıv1 & 87.5 & 3 & 61.25 & 366.64 & 1.16339 \\
\hline 9 & S1k1ştırılmş sıv1 & 105.5 & 1.9 & 61.25 & 442.380 & 1.36863 \\
\hline 10 & S1k1ştırılmş sıv1 & 106 & 49 & 61.25 & 445.86 & 1.36481 \\
\hline 11 & Sik1ştırılmş S1V1 & 148.8 & 48 & 61.25 & 629.875 & 1.82513 \\
\hline 12 & Buhar & 233.5 & 5.71 & 46.521 & 2922.84 & 7.136 \\
\hline 13 & Buhar & 210 & 5.38 & 20.3 & 2874.38 & 7.06518 \\
\hline 14 & S1kıştırılmş sıvı & 125 & 2.31 & 20.3 & 525.102 & 1.58154 \\
\hline 15 & Buhar & 210 & 5.38 & 15.821 & 2874.38 & 7.06518 \\
\hline 16 & S1kıştırılmş sıvı & 125 & 2.31 & 15.821 & 525.102 & 1.58154 \\
\hline 17 & Buhar & 210 & 5.38 & 0.5 & 2874.38 & 7.06518 \\
\hline 18 & S1k1ştırılmş sıv1 & 90 & 1 & 0.5 & 376.993 & 1.19257 \\
\hline 19 & Buhar & 210 & 5.38 & 1.1 & 2874.38 & 7.06518 \\
\hline 20 & Buhar & 210 & 2.85 & 2.3 & 2886.24 & 7.37621 \\
\hline 21 & Sıkıştırılmş Sıv1 & 110 & 1.419 & 2.3 & 461.372 & 1.41862 \\
\hline 22 & Buhar & 210 & 3.6 & 5 & 2882.79 & 7.26338 \\
\hline 23 & S1k1ştırılmş sıv1 & 95 & 1 & 5 & 398.029 & 1.25010 \\
\hline 24 & Buhar & 210 & 5.38 & 1.5 & 2874.38 & 7.06518 \\
\hline 25 & S1k1ştırılmş sıv1 & 21.4 & 3 & 1.198 & 90.0062 & 0.316125 \\
\hline 26 & S1k1ştırılmş sıv1 & 28.9 & 1 & 1.198 & 121.192 & 0.421349 \\
\hline 27 & S1k1ştırılmş sıv1 & 20 & 1 & 11.458 & 83.962 & 0.296242 \\
\hline 28 & S1k1ştırılmş sıv1 & 95 & 1 & 3.05 & 398.029 & 1.25010 \\
\hline 29 & Sıkıştırılmş sıvı & 87.5 & 1 & 4.3 & 366.486 & 1.16353 \\
\hline 30 & S1k1ştırılmş sıv1 & 87.5 & 11 & 4.3 & 367.265 & 1.16283 \\
\hline 31 & S1k1ştırılmş sıv1 & 154 & 5.38 & 4.3 & 649.657 & 1.88267 \\
\hline
\end{tabular}


$\mathrm{Bu}$ birimlerin dışında tesiste çalışan pompaların Termodinamik özellikleri de pompa verileri yardımıyla hesaplanmış ve Tablo 2'de sunulmuştur. Düğüm noktalarındaki değerlerin hesaplanması için her bir komponent için enerji ve ekserji dengeleri kurulmuş ve Tablo 3'te verilmiştir. Ayrıca her bir ekipmanın sembolik şekli de Tablo 3'te gösterilmiştir.

Tablo 2. Kojenerayon Sistemi’nde Bulunan Pompalar ve Termodinamik Özellikleri

\begin{tabular}{|c|c|c|c|c|c|c|c|c|c|}
\hline \multirow{2}{*}{$\begin{array}{l}\text { Pompa } \\
\text { Tipi }\end{array}$} & \multirow{2}{*}{$\begin{array}{l}\text { Güç } \\
(\mathbf{k W})\end{array}$} & \multicolumn{2}{|c|}{$\dot{\mathbf{m}}(\operatorname{ton} / \mathbf{s})$} & \multicolumn{2}{|c|}{$\mathbf{P}$ (bar) } & \multicolumn{2}{|c|}{$\mathbf{T}\left({ }^{\circ} \mathbf{C}\right)$} & \multicolumn{2}{|c|}{ h (kJ/kg) } \\
\hline & & Giriș & Çıkıs & Giriș & Çıkıș & Giriş & Çıkıș & Giriş & Çıkış \\
\hline $\begin{array}{l}\text { Buhar Soğutma } \\
\text { Pompası }\end{array}$ & 7.5 & 4.3 & 4.3 & 1 & 11 & 87.5 & 87.5 & 366.486 & 367.265 \\
\hline $\begin{array}{l}\text { Kondenser } \\
\text { Pompas1 }\end{array}$ & 18.5 & 17.479 & 17.479 & 0,4 & 5.75 & 50.272 & 50.272 & 210.524 & 210.985 \\
\hline $\begin{array}{l}\text { Degazör Besleme } \\
\text { Pompası }\end{array}$ & 11 & 61.25 & 61.25 & 1 & 3 & 87.5 & 87.5 & 366.48 & 366.64 \\
\hline $\begin{array}{l}\text { Kazan Besleme } \\
\text { Pompas1 }\end{array}$ & 160 & 61.25 & 61.25 & 1.9 & 49 & 105.5 & 106 & 1.36863 & 1.36481 \\
\hline
\end{tabular}

Tablo 3. Kojenerayon Tesisi'ne Ait Komponentlerin Enerji ve Ekserji Dengeleri

\begin{tabular}{|c|c|c|c|}
\hline \multicolumn{4}{|c|}{ Enerji ve Ekserji Dengeleri } \\
\hline Ünite & Ünitenin Şekli & Enerji Dengesi & Ekserji Dengesi \\
\hline Kazan & 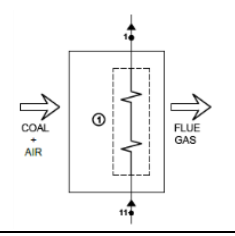 & $\begin{array}{l}\dot{Q}_{1}=\dot{m}_{1} \cdot h_{1}-\dot{m}_{11} \cdot h_{11} \\
-\dot{E}_{\text {Yaklt }}-\dot{E}_{\text {Hava }} \\
+\dot{E}_{\text {BacaGazl }}\end{array}$ & $\begin{array}{l}\dot{E} X_{\text {Yakt }}+\dot{E} X_{\text {Hava }}+\dot{E} X_{11} \\
=\dot{E} X_{1}+\dot{E} X_{\text {BacaGazl }} \\
+\dot{E} X_{\text {Kaylp }}+\dot{E} X_{\text {Ylkm }}\end{array}$ \\
\hline Türbin & & $\begin{array}{l}\dot{Q}_{3}-\dot{W}_{1}=\dot{m}_{4} \cdot h_{4} \\
+\dot{m}_{12} \cdot h_{12}-\dot{m}_{3} \cdot h_{3}\end{array}$ & $\begin{array}{l}\dot{E} X_{3}=\dot{E} X_{4}+\dot{E} X_{12} \\
+\dot{E} X_{w, t u ̈ r b i n}+\dot{E} X_{\text {Kaylp }} \\
+\dot{E} X_{Y k k m}\end{array}$ \\
\hline Kondenser & $\frac{46}{5}$ & $\begin{array}{l}\dot{Q}_{5}=\dot{m}_{5} \cdot h_{5}+\dot{m}_{26} \cdot h_{26} \\
-\dot{m}_{4} \cdot h_{4}-\dot{m}_{25} \cdot h_{25}\end{array}$ & $\begin{array}{l}\dot{E} X_{4}+\dot{E} X_{25}=\dot{E} X_{4} \\
+\dot{E} X_{26}+\dot{E} X_{\text {Kaylp }} \\
+\dot{E} X_{Y l k m}\end{array}$ \\
\hline $\begin{array}{l}\text { Yüksek Basınçlı } \\
\text { Isıtıcı }\end{array}$ & $-\left.4\right|^{23}$ & $\begin{array}{l}\dot{Q}_{8}=\dot{m}_{11} \cdot h_{11}+\dot{m}_{23} \cdot h_{23} \\
-\dot{m}_{10} \cdot h_{10}-\dot{m}_{22} \cdot h_{22}\end{array}$ & $\begin{array}{l}\dot{E} X_{10}+\dot{E} X_{22} \\
=\dot{E} X_{11}+\dot{E} X_{23} \\
+\dot{E} X_{\text {Kaylp }}+\dot{E} X_{\text {Ylkm }}\end{array}$ \\
\hline Degazör & 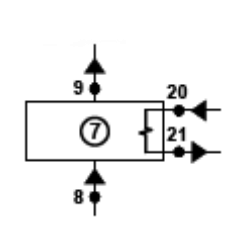 & $\begin{array}{l}\dot{Q}_{7}=\dot{m}_{9} \cdot h_{9}+\dot{m}_{21} \cdot h_{21} \\
-\dot{m}_{8} \cdot h_{8}-\dot{m}_{20} \cdot h_{20}\end{array}$ & $\begin{array}{l}\dot{E} X_{8}+\dot{E} X_{20} \\
=\dot{E} X_{9}+\dot{E} X_{21} \\
+\dot{E} X_{\text {Kaylp }}+\dot{E} X_{\text {Ylkm }}\end{array}$ \\
\hline & & & \\
\hline
\end{tabular}




\begin{tabular}{|c|c|c|c|}
\hline \multicolumn{4}{|l|}{ ablo 3'ün Devamı } \\
\hline Kondensat Tank1 & 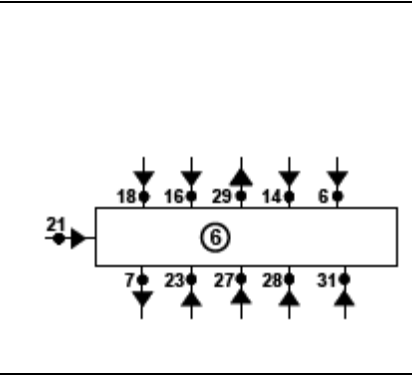 & $\begin{array}{l}\dot{Q}_{6}=\dot{m}_{7} \cdot h_{7}+\dot{m}_{29} \cdot h_{29} \\
-\dot{m}_{6} \cdot h_{6}-\dot{m}_{14} \cdot h_{14} \\
-\dot{m}_{16} \cdot h_{16}-\dot{m}_{18} \cdot h_{18} \\
-\dot{m}_{21} \cdot h_{21}-\dot{m}_{23} \cdot h_{23} \\
-\dot{m}_{27} \cdot h_{27}-\dot{m}_{28} \cdot h_{28} \\
-\dot{m}_{31} \cdot h_{31}\end{array}$ & $\begin{array}{l}\dot{E} X_{7}+\dot{E} X_{29}=\dot{E} X_{6} \\
+\dot{E} X_{14}+\dot{E} X_{16}+\dot{E} X_{18} \\
+\dot{E} X_{21}+\dot{E} X_{23}+\dot{E} X_{27} \\
+\dot{E} X_{28}+\dot{E} X_{31}+\dot{E} X_{\text {Kayp }} \\
+\dot{E} X_{Y k k m}\end{array}$ \\
\hline Makine Kollektörü & 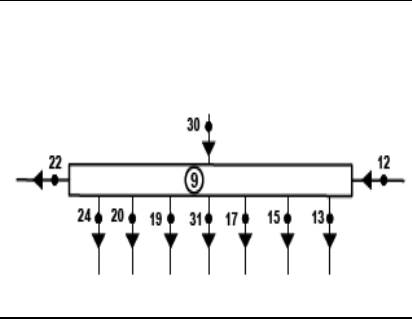 & $\begin{array}{l}\dot{Q}_{9}=\dot{m}_{13} \cdot h_{13}+\dot{m}_{15} \cdot h_{15} \\
+\dot{m}_{17} \cdot h_{17}+\dot{m}_{19} \cdot h_{19} \\
+\dot{m}_{20} \cdot h_{20}+\dot{m}_{22} \cdot h_{22} \\
+\dot{m}_{24} \cdot h_{24}+\dot{m}_{31} \cdot h_{31} \\
-\dot{m}_{12} \cdot h_{12}-\dot{m}_{30} \cdot h_{30}\end{array}$ & $\begin{array}{l}\dot{E} X_{12}+\dot{E} X_{30}=\dot{E} X_{13} \\
+\dot{E} X_{15}+\dot{E} X_{17}+\dot{E} X_{19} \\
+\dot{E} X_{20}+\dot{E} X_{22}+\dot{E} X_{24} \\
+\dot{E} X_{31}+\dot{E} X_{\text {Kayp }}+\dot{E} X_{Y l k m}\end{array}$ \\
\hline PM1 & $\overbrace{140}^{13+}$ & $\dot{Q}_{10}=\dot{m}_{14} \cdot h_{14}-\dot{m}_{13} \cdot h_{13}$ & $\begin{array}{l}\dot{E} X_{13}=\dot{E} X_{14} \\
+\dot{E} X_{\text {Kayp }}+\dot{E} X_{Y l k m}\end{array}$ \\
\hline PM2 & $\overbrace{160}^{15+}$ & $\dot{Q}_{11}=\dot{m}_{16} \cdot h_{16}-\dot{m}_{15} \cdot h_{15}$ & $\begin{array}{l}\dot{E} X_{15}=\dot{E} X_{16} \\
+\dot{E} X_{\text {Kaylp }}+\dot{E} X_{Y l k m}\end{array}$ \\
\hline Kalorifer & $\overbrace{180}^{17+}$ & $\dot{Q}_{12}=\dot{m}_{18} \cdot h_{18}-\dot{m}_{17} \cdot h_{17}$ & $\begin{array}{l}\dot{E} X_{17}=\dot{E} X_{18} \\
+\dot{E} X_{\text {Kaylp }}+\dot{E} X_{Y_{l k m}}\end{array}$ \\
\hline Termo Kompresör & 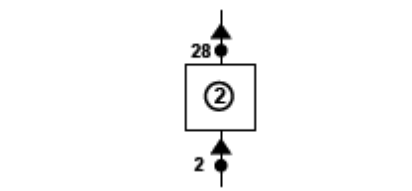 & $\dot{Q}_{2}=\dot{m}_{28} \cdot h_{28}-\dot{m}_{2} \cdot h_{2}$ & $\begin{array}{l}\dot{E} X_{2}=\dot{E} X_{28} \\
+\dot{E} X_{\text {Kaylp }}+\dot{E} X_{Y l k m}\end{array}$ \\
\hline $\begin{array}{l}\text { Buhar Soğutma } \\
\text { Pompası }\end{array}$ & ${ }_{29}^{300}$ & $\begin{array}{l}\dot{Q}_{B S P}=\dot{W}_{B S P}+\dot{m}_{29} \cdot h_{29} \\
-\dot{m}_{30} \cdot h_{30}\end{array}$ & $\begin{array}{l}\dot{E} X_{B S P}+\dot{E} X_{29} \\
=\dot{E} X_{30}+\dot{E} X_{\text {Kayp }} \\
+\dot{E} X_{Y l k l m}\end{array}$ \\
\hline Kondenser Pompası & $\prod_{6}^{50}$ & $\begin{array}{l}\dot{Q}_{K P}=\dot{W}_{K P}+\dot{m}_{6} \cdot h_{6} \\
-\dot{m}_{5} \cdot h_{5}\end{array}$ & $\begin{array}{l}\dot{E} X_{B S P}+\dot{E} X_{29} \\
=\dot{E} X_{30}+\dot{E} X_{K a y p} \\
+\dot{E} X_{Y k k m}\end{array}$ \\
\hline $\begin{array}{l}\text { Degazör Besleme } \\
\text { Pompas1 }\end{array}$ & 8 & $\begin{array}{l}\dot{Q}_{D S P}=\dot{W}_{D S P}+\dot{m}_{8} \cdot h_{8} \\
-\dot{m}_{7} \cdot h_{7}\end{array}$ & $\begin{array}{l}\dot{E} X_{D S P}+\dot{E} X_{7} \\
=\dot{E} X_{8}+\dot{E} X_{\text {Kayp }} \\
+\dot{E} X_{Y \text { Iklm }}\end{array}$ \\
\hline $\begin{array}{l}\text { Kazan Besleme } \\
\text { Pompası }\end{array}$ & $\oint_{90}^{10 \phi}$ & $\begin{array}{l}\dot{Q}_{K S P}=\dot{W}_{K S P}+\dot{m}_{10} \cdot h_{10} \\
-\dot{m}_{9} \cdot h_{9}\end{array}$ & $\begin{array}{l}\dot{E} X_{K S P}+\dot{E} X_{9} \\
=\dot{E} X_{10}+\dot{E} X_{\text {Kayp }} \\
+\dot{E} X_{Y k l m}\end{array}$ \\
\hline
\end{tabular}


Tablo 1 ve Tablo 2'deki değerlerin yardımıyla mevcut 31 adet düğüm noktası için enerji (Denklem 7), fiziksel ekserji (Denklem 13), kimyasal ekserji (Denklem 14) ve toplam ekserji (Denklem 9) değerleri hesaplanmış ve Tablo 4'te verilmiştir. 1 numaralı ve 3 numaralı dügüumler kazan ve türbini göstermektedir. En yüksek enerji ile fiziksel ve kimyasal ekserji değerleri kazan ve türbinde olmuştur.

Tablo 4'teki değerler ile (8) ve (18) numaralı denklemler kullanılarak Kojenerasyon sisteminin 1s1l verimi \%80.15 ve ekserji verimi \%32.75 olarak bulunmuştur.

Tablo 4. Kojenerasyon Tesisi'ne Ait Enerji ve Ekserji Değerleri

\begin{tabular}{|c|c|c|c|c|}
\hline \multicolumn{5}{|c|}{ Kojenerasyon Tesisine Ait Enerji ve Ekserji Değerleri } \\
\hline Düğüm & Enerji & Fiziksel Ekserji & Kimyasal Ekserji & Toplam Ekserji \\
\hline Noktası & $\dot{\mathbf{E}}(\mathbf{k W})$ & $\dot{\mathbf{E}} \mathbf{X}^{\mathrm{PH}}(\mathbf{k W})$ & $\dot{\mathbf{E}} \mathbf{X}^{\mathrm{CH}}(\mathbf{k W})$ & $\dot{\mathbf{E X}}(\mathbf{k W})$ \\
\hline 1 & 56969.31 & 21850.59 & 42.53 & 21893.13 \\
\hline 2 & 2836.84 & 1088.07 & 2.12 & 1090.19 \\
\hline 3 & 54173.05 & 20475.50 & 40.42 & 20515.91 \\
\hline 4 & 1971.14 & 622.05 & 8.11 & 630.16 \\
\hline 5 & 682.97 & 14.09 & 8.11 & 22.20 \\
\hline 6 & 684.47 & 15.88 & 8.11 & 23.99 \\
\hline 7 & 6235.25 & 414.18 & 42.53 & 456.72 \\
\hline 8 & 6237.97 & 417.61 & 42.53 & 460.15 \\
\hline 9 & 7526.60 & 665.65 & 42.53 & 708.18 \\
\hline 10 & 7585.81 & 744.23 & 42.53 & 786.76 \\
\hline 11 & 10716.62 & 1541.15 & 42.53 & 1583.68 \\
\hline 12 & 37770.40 & 10349.73 & 32.31 & 10382.03 \\
\hline 13 & 16208.31 & 4361.97 & 14.10 & 4376.07 \\
\hline 14 & 2960.99 & 329.30 & 14.10 & 343.40 \\
\hline 15 & 12632.10 & 3399.55 & 10.99 & 3410.53 \\
\hline 16 & 2307.68 & 256.65 & 10.99 & 267.63 \\
\hline 17 & 399.22 & 107.44 & 0.35 & 107.78 \\
\hline 18 & 52.36 & 3.64 & 0.35 & 3.99 \\
\hline 19 & 878.28 & 236.36 & 0.76 & 237.13 \\
\hline 20 & 1843.99 & 442.57 & 1.60 & 444.17 \\
\hline 21 & 294.77 & 27.61 & 1.60 & 29.21 \\
\hline 22 & 4003.88 & 1004.03 & 3.47 & 1007.50 \\
\hline 23 & 552.82 & 41.80 & 3.47 & 45.27 \\
\hline 24 & 1197.66 & 322.31 & 1.04 & 323.35 \\
\hline 25 & 29.95 & 0.13 & 0.83 & 0.96 \\
\hline 26 & 40.33 & 0.08 & 0.83 & 0.91 \\
\hline 27 & 60.64 & 0.88 & 7.96 & 8.84 \\
\hline 28 & 337.22 & 25.50 & 2.12 & 27.62 \\
\hline 29 & 437.75 & 29.08 & 2.99 & 32.07 \\
\hline 30 & 438.68 & 30.26 & 2.99 & 33.25 \\
\hline 31 & 775.98 & 111.34 & 2.99 & 114.33 \\
\hline
\end{tabular}


Tablo 5'te komponentler için sirasıyla giren enerji, çıkan enerji, kayıp enerji ve bu enerji kaybının tesisteki toplam enerji kaybına olan oranı verilmiştir. Kayıp enerjinin ve enerji kayıp oranının en fazla olduğu ekipmanın sırasıyla \%97.39 ile buhar tüketim grubu ve \%42.92 değeri ile kazan olduğu görülmüştür.

Tablo 5. Ünite Bileşenleri için Enerji Değerleri

\begin{tabular}{|c|c|c|c|c|}
\hline \multirow{2}{*}{ Üniteler } & Giren Enerji & Çıkan Enerji & Kayıp Enerji & Enerji Kaybı Oranı \\
\hline & $(\mathbf{k W})$ & $(\mathbf{k W})$ & $(\mathbf{k W})$ & $\%$ \\
\hline Kazan & 76421.31 & 64778.15 & 11643.17 & 42.92 \\
\hline Türbin & 54173.05 & 48766.54 & 5406.50 & 19.93 \\
\hline Kondenser & 8437.89 & 723.30 & 7714.59 & 28.44 \\
\hline Yüksek Basınçlı Isıtıcı & 11589.69 & 11269.44 & 320.25 & 1.18 \\
\hline Yardımcı Grup & 54335.57 & 52433.78 & 1901.79 & 7.01 \\
\hline Buhar Tüketim Grubu & 32076.47 & 5658.25 & 26418.22 & 97.39 \\
\hline Pompa Grubu & 15426.92 & 15286.85 & 140.07 & 0.52 \\
\hline Toplam & 252460.90 & 198916.32 & 27126.36 & 100.00 \\
\hline
\end{tabular}

Aynı şekilde Tablo 6'da ise Ekserji girdi, çıktı, ve kayıp değerleri verilmiş olup yine tesisteki toplam ekserji kaybına oranı da hesaplanarak elde edilmiştir.
Tablo 6 incelendiğinde; yıkılan ekserji, yok olan ekserji ve kayıp ekserji oranlarının en yüksek olduğu yerin kazan olduğu görülmektedir.

Tablo 6. Ünite Bileşenleri için Ekserji Değerleri

\begin{tabular}{|c|c|c|c|c|c|c|}
\hline \multirow[t]{2}{*}{ Üniteler } & $\begin{array}{c}\text { Giren } \\
\text { Ekserji }\end{array}$ & $\begin{array}{c}\text { Çıkan } \\
\text { Ekserji }\end{array}$ & $\begin{array}{c}\text { Ekserji } \\
\text { Kaybı }\end{array}$ & $\begin{array}{l}\text { Yıkılan } \\
\text { Ekserji }\end{array}$ & $\begin{array}{c}\text { Yok Olan } \\
\text { Ekserji }\end{array}$ & $\begin{array}{c}\text { Kayıp Ekserji } \\
\text { Oranı }\end{array}$ \\
\hline & $(k W)$ & $(k W)$ & $(\mathbf{k W})$ & $(k W)$ & $(k W)$ & $\%$ \\
\hline Kazan & 60306.97 & 26832.21 & 1818.27 & 31656.49 & 33474.76 & 87.30 \\
\hline Türbin & 20515.91 & 20037.19 & 420.78 & 57.95 & 508.67 & 1.33 \\
\hline Kondenser & 631.12 & 64.58 & 373.23 & 193.32 & 383.46 & 1.00 \\
\hline $\begin{array}{l}\text { Yüksek Basınçlı } \\
\text { Isıtıcı }\end{array}$ & 1794.26 & 1628.95 & 20.28 & 145.02 & 112.20 & 0.29 \\
\hline Yardımcı Grup & 12178.07 & 11247.05 & 92.60 & 838.42 & 249.77 & 0.65 \\
\hline $\begin{array}{l}\text { Buhar Tüketim } \\
\text { Grubu }\end{array}$ & 8984.58 & 642.64 & 3483.18 & 4858.76 & 3505.11 & 9.14 \\
\hline Pompa Grubu & 1416.17 & 1304.15 & 4.61 & 107.41 & 110.30 & 0.29 \\
\hline Toplam & 105827.09 & 61756.76 & 6212.95 & 37857.37 & 38344.27 & 100.00 \\
\hline
\end{tabular}

Şekil 2'de bu çalıșmanın yapıldığ Kahramanmaraş Kağıt San. ve Tic. A.Ş. Kojenerasyon tesisi ekipmanlarının enerji kayıp oranları gösterilmiştir. Bu grafiğe göre en yüksekten en düşüğe toplam enerji kaybının görüldüğü ekipmanlar sirasıyla; \%42.92'si ile kazan, \%28.43'ü ile kondenser, \%19.93'ü ile türbin, \%7.01'i ile yardımcı grup, \%1.18'i ile yüksek basınçlı ısıtıcı ve $\% 0.51$ 'i ile pompa grubudur. Tesis standart bir enerji santralinden farklı olarak bir kojenerasyon tesisi olması sebebiyle üretilen enerjinin büyük bir kısmı, kağıt üretim prosesinde değerlendirilen buhar tüketim grubunda tüketilmektedir. Burada bir tüketim söz konusu olduğundan, buhar tüketim grubunda harcanan enerji, kayıp olarak değerlendirilmemiştir. Buna göre kazan ve kondenser enerji kaybının değerlendirilmesi açısından öncelikli sıradadır. 


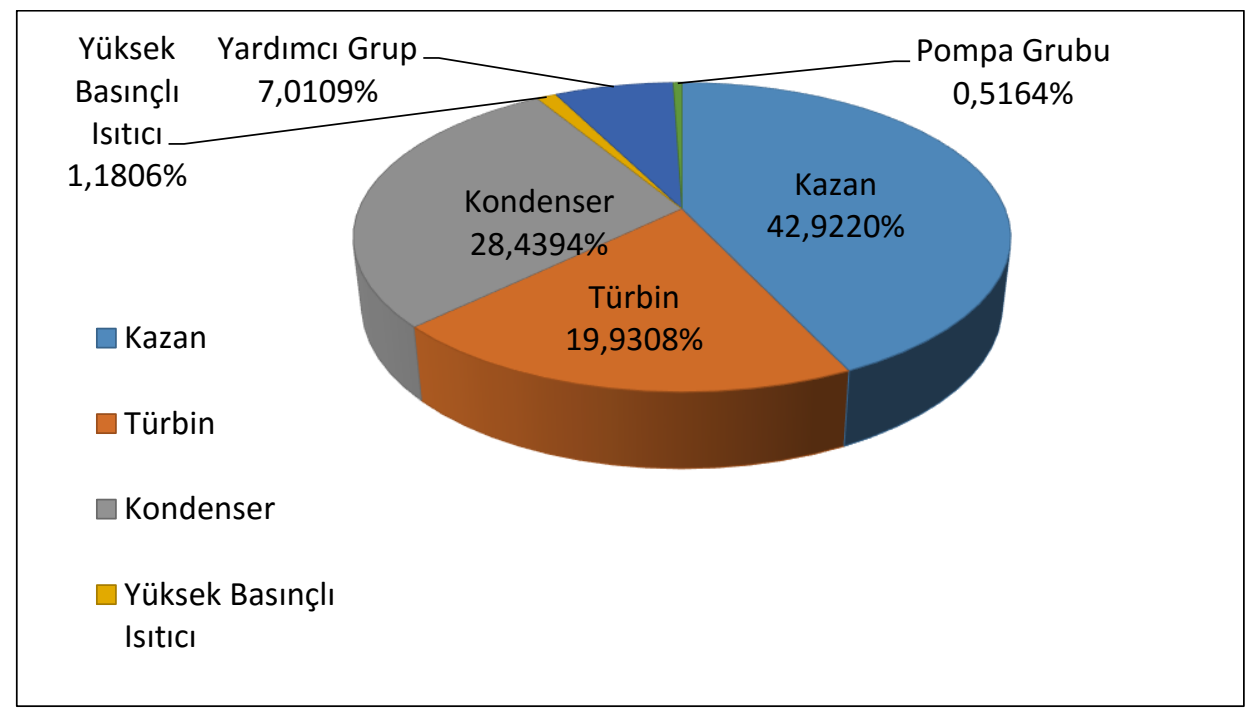

Şekil 2. Kojenerasyon Tesisi Enerji Kayıp Oranlar

Şekil 3'te ise kojenerasyon tesisi ekipmanlarının ekserji kayıp oranları verilmiştir. Bu grafiğe göre en yüksekten en düşüğe ekserji kaybı değerlerinin olduğu ekipmanlar sırasıyla; toplam ekserji kaybının $\% 87.3$ 'ü ile kazan, \%9.14'ü ile buhar tüketim grubu, $\% 1.33$ 'ü ile türbin, \%1'i ile kondenser, $\% 0.65$ 'i ile yardımcı grup, \%0.29'u ile yüksek basınçlı ısıtıcı ve
$\% 0.29$ 'i ile pompa grubudur. Şekil 3'ten de görüldüğü gibi, ekserji kaybının en yüksek olduğu ekipmanlar kazan ve buhar tüketim grubudur. Diğer ekipmanların ekserji kayıları ise kazan ve buhar tüketim grubuna nazaran son derece düşüktür.

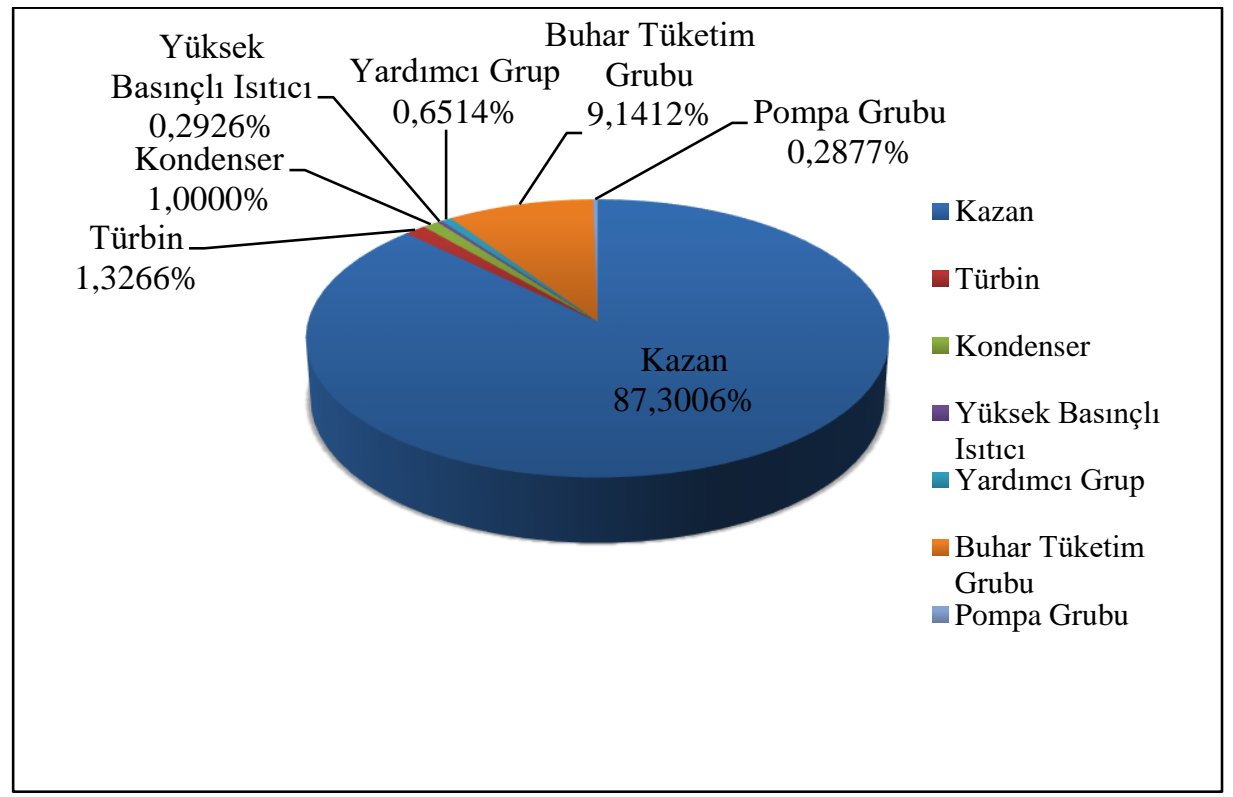

Şekil 3. Kojenerasyon Tesisi Ekserji Kayıp Oranları

Enerji ve Ekserji verimleri göze alındığında öncelikli iyileştirme planlarının kazan üzerinde olması gerektiği anlaşılmaktadır. Buhar kazanı veriminin artmas1 için en önemli parametrelerden biri yanma veriminin arttırılmasıdır. Bunun için kömür besleme sistemlerinde, yakıcılarda, kazan içerisinde bulunan reküperatif tip hava isitıcılarda revizyonlar yapılmalıdır. Bunun yanı sıra buhar kazanının verimliliğini belirleyen bir diğer önemli faktörde ısının su ve buhara geçerken karşılaş̧ı̆̆ 1 dirençlerdir. $\mathrm{Bu}$ dirençlerin en aza indirilebilmesi için kazan içerisinde bulunan kızdırıcı ve ekonomizer borularının yenilenmesi ve bu sayede zamanla cüruf kaplanan bu borularda oluşan 1s1l direncin ortadan kaldırılması gerekmektedir. Ayrıca kazan ve bağlı sistemlerin 1s1 yalıtımlarının iyileştirilmesi de düşünülmelidir. 
Kazandan sonra en yüksek enerji kaybının görüldüğü ekipman kondenserdir. Ancak kondenserdeki enerji kaybı durumuna farklı yaklaşmak gerekmektedir. Kondenser sonrasında çalı̧̧an kondens ve besi suyu pompaları tek fazlı sistemle çalışan bir ekipmandır ve pompaya gelen akışkanın sıvı olması zorunludur [8]. Bu sebeple çevrimde kendine yer bulan kondenser akışkanı gaz fazından sıvı fazına dönüştürürken, yüksek miktardaki enerji soğutma kulesi vasıtasıyla dışarı atılmaktadır. Bu noktada kondensere yapılabilecek bir müdahale mümkün olmamaktadır.

Türbin enerji kaybı oranı sıralamasında üçüncü sırada yer almaktadır, fakat türbinde yapılabilecek iyileștirmelerin çok maliyetli olması ve geri dönüş sürelerinin uzunluğu sebebiyle ile türbinde yalnızca ara çekiş kontrollerinin hassasiyetinin yükseltilmesi verimli bir müdahale olabilir. Benzer sonuçlar termik santrale uygulanan enerji ve ekserji analizinde de elde edilmiștir [8].

Tüm bunların dışında, üzerinde çalışılmış olan kojenerasyon tesisi, operatörlerin vasitasıyla analog kontrolörler ile yönetilmektedir. Bu nedenle işletme esnasında insan hatası faktöründen kaynaklanan verimsizlikler olabilmektedir. Sistemin geneline uygulanacak bir otomasyon sistemi ile bu hataların ortadan kaldırılması akabinde sistem genelinde bir verim artışı olacağı düşünülmektedir.

Fosil yakıtların sınırlı olması ve çevreye salınan egzoz gazları göze alındığında bu tarz tesislerin verimli çalışması son derece önemlidir. Verimliliăgi tesis edebilmek adına tesisin tamamına uygulanacak olan iyileştirmelerin önemi açıça görülmektedir.

\section{SONUÇLAR}

Halen çalışmakta olan Kahramanmaraş Kağıt San. ve Tic. A.Ş Kojenerasyon Tesisi'nin tespit edilen parametrelere göre Termodinamik analizi yapılmıştır. Çalışma sonucunda elde edilenler aşağıda verilmiştir;

- Santralde toplam enerji kaybının \%42.92'si kazanda, \%28.43'ü kondenserde ve \%19.93'nün de türbinde olduğu belirlenmiştir.

- Toplam ekserji kaybının ise \%87.3'ü kazanda, $\% 9.14$ 'ü buhar tüketim grubunda ve $\% 1.33$ 'ü de türbinde olduğu tespit edilmiştir.

- Enerji ve Ekserji verimleri göze alındığında öncelikli iyileştirmenin kazanda olması gerektiği anlaşılmaktadır.

\section{SEMBOLLER ve KISALTMA LISTESI}

$\begin{array}{ll}\mathrm{c} & \text { Çıkış } \\ \mathrm{E} & \text { Enerji, } \mathrm{kJ} / \mathrm{kg} \\ \mathrm{Ex} & \text { Özgül ekserji, kJ/kg } \\ \mathrm{g} & \text { Giriş } \\ \mathrm{h} & \text { Entalpi, } \mathrm{kJ} / \mathrm{kg} \\ \mathrm{ky} & \text { Kayıp } \\ \mathrm{m} & \text { Kütle, } \mathrm{kg} \\ \dot{m} & \text { Kütlesel debi, } \mathrm{kg} / \mathrm{s} \\ Q & \text { Isı, } \mathrm{kJ} \\ \mathrm{s} & \text { Entropi, } \mathrm{kJ} / \mathrm{kgK} \\ \mathrm{T} & \text { Sıcaklık, K } \\ \mathrm{W} & \text { İs, J } \\ \mathrm{y} & \text { Yok edilen ekserji oranı, birimsiz } \\ & \\ \text { alt indisler } & \\ P H & \text { Fiziksel ekserji } \\ C H & \text { Kimyasal ekserji } \\ P T & \text { Potansiyel ekserji } \\ K N & \text { Kinetik ekserji }\end{array}$

\section{KAYNAKLAR}

[1]. Ball1, Ö., "Kojenerasyon Sistemlerinin Enerji, Kullanılabilirlik (Ekserji) ve Ekserjiekonomik Analiz Yöntemleri Kullanılarak Performansının Değerlendirilmesi”, Eskişehir Osmangazi Üniversitesi, Fen Bilimleri Enstitüsü, Yüksek Lisans Tezi, Eşkişehir, Haziran 2008.

[2]. Yazıcı, H., Selbaş, R., "Bir buharlı güç santralinin enerji ve ekserji analizi", Selçuk Üniversitesi-Teknik Online Dergi, 10 (2011) $117-135$

[3]. Rahim, M.A., Gündüz, D., “Gaz türbinli bir 1s1lgüç (kojenerasyon) çevrim santralinin enerji ve ekserji analizi:Ankara Şartlarında Uygulama", Türk Bilim Araştırma Vakfi, 6 (2) (2013) 19-27.

[6]. Sevilgen, S.H., "Kojenerasyon Sisteminin Ekserjoekonomik Analizi" Journal of Engineering and Natural Sciences-Sigma, 4 (2004) 234-248

[4]. Colpan, C. O., Yesin, T., "Energetic, exergetic and thermoeconomic analysis of Bilkent combined cycle cogeneration plant", Mechanical Engineering Department, Middle East Technical University, 06531 Ankara, Turkey, 2006.

[5]. Coşkun, A., Geredelioğlu, Ç., Bolattürk, A., Gökaslan, M. Y. , "Çayırhan Termik Santralinin Enerji ve Ekserji Analizi", 11. Ulusal Tesisat Mühendisliği Kongresi, 17/20 Nisan 2013, İzmir.

[7]. Rosen, M.A and Dinçer,I.., "Effect of Varying dead-state properties on energy and exergy analysis of thermal systems", International 
Journal of Thermal Science, 43 (2) (2004) 121133.

[8]. Ünal, F., Özkan, D.,B., “Tunçbilek Termik Santralinin Enerji ve Ekserji Analizi”, Tesisat Mühendisliği, 143 (2014) 5-13.

[9]. Kaya, M., "Buharlı Güç Çevrim Veriminin Ekserji Analiziyle Belirlenmesi”, CBÜ Soma Meslek Yüksekokulu Teknik Bilimler Dergisi, Cilt:1, Sayı: 9, Soma, 2008.

[10]. Bejan, A., Tsatsaronis, G., Moran, M., "Thermal Design and Optimization", 1996.

[11]. Çengel, Y. A., Boles, M. A, "Mühendislik Yaklasımiyla Termodinamik", McGraw-Hill Literatür Ortak Yayını, (Çev. T. Derbentli), 1996. 